\title{
Volume of clinical activity in hospitals and healthcare outcomes, costs, and patient access
}

\author{
Amanda Sowden, Vassilis Aletras, Michael Place, Nigel Rice, Alison Eastwood, \\ Roberto Grilli, Brian Ferguson, John Posnett, Trevor Sheldon
}

\section{NHS Centre for Reviews and Dissemination Amanda Sowden, research fellow Vassilis Aletras, visiting research fellow Alison Eastwood, research fellow \\ Trevor Sheldon, director \\ Centre for Health \\ Economics \\ Nigel Rice, research \\ fellow \\ Brian Ferguson, deputy \\ director}

\section{York Health \\ Economics \\ Consortium, \\ University of York \\ Michael Place, research \\ fellow \\ John Posnett, director}

\section{Instituti di Recerche Farmacologiche "Mario Negri", Milan, Italy \\ Roberto Grilli, clinical} epidemiologist

Correspondence to: Professor Trevor A Sheldon, NHS Centre for Reviews and Dissemination, University of York, York YO1 5DD, UK.

\begin{abstract}
Background
Concentration of the provision of hospital services is sometimes seen as a way to reduce costs and improve the quality and efficiency of care. This paper, based on an issue of Effective Health Care Vol 2, No 8 summarises the results of systematic reviews carried out at the University of York to assess research into the possible relation between volume of clinical activity in hospitals and the outcomes of quality of health care, hospital costs (economies of scale), and patient access. Full reports of the methods used and the results of these reviews, including details of the studies included, are available from the National Health Service (NHS) Centre for Reviews and Dissemination and cannot be presented here due to lack of space. $^{1-4}$
\end{abstract}

\section{Volume and outcomes}

There is considerable interest in whether improved outcomes of health care can be gained from concentrating the hospital care of particular conditions or procedures. This may involve fewer clinicians or hospitals providing higher volumes of activity. Against this background, a systematic review of the research was conducted to assess the evidence for a relation between hospital or doctor volume and patient outcomes. ${ }^{2}$

More than 200 (mainly observational) studies were included; most reported a reduction in poor health outcomes (principally hospital mortality) as volumes increased. The apparent strength of this finding may be misleading, because of the inadequate handling in many studies of differences in patient case mix between hospitals and doctors.

\section{Adjustment for case mix}

Studies of hospital mortalities need to distinguish between the effects of differences in severity of illness and differences in quality of care. Higher mortalities may be due to a higher proportion of emergency or urgent cases, whereas lower mortalities may reflect the better results obtained from treating a lower risk patient population. Variations in case mix have a crucial influence on the interpretation of outcome data based on observational studies. Unmeasured dif- ferences in patient populations between hospitals or doctors with different volumes result in misleading results (confounding). ${ }^{5}$

The more that patient characteristics which influence health outcome are taken into account-for example by statistical adjustment-the more likely it is to obtain an unbiased assessment of the association between hospital or physician volume and outcome. $^{6}$ Routine hospital data are rarely sufficiently detailed to adjust adequately for case mix. Studies that adjust for risk of death based on detailed clinical data are the most valid.

All the studies identified were graded on a four point scale from 0 -III where 0 indicates no adjustment, I adjustment for age and sex only, II for some clinical risk factors, and III indicates more extensive adjustment with validated clinical risk factors or scores.

The importance of adequate adjustment is well illustrated in studies of coronary artery bypass graft surgery (CABG) and also intensive care. In the case of CABG, the size of the relation between low volume $(<200$ procedures a year) and increased mortality is reduced in studies which better adjust for differences in patient risk (figure) ${ }^{7}$ In the case of adult intensive care in the United Kingdom, where well validated prognostic indicators have been developed (APACHE II), higher mortality found in smaller intensive care units with unadjusted data were no longer significant after adjusting for case mix. The average level of severity was higher in patients admitted to smaller units. $^{8}$

Only one study identified used a randomised controlled trial design to evaluate the effect of differences in volume per clinician in comparable groups of patients. ${ }^{18}$ In this study of 50 patients at two university hospitals no differences in clinical outcome (or total costs) were found between the two groups receiving angioplasty.

Most studies identified did not sufficiently take into account the effects of differences in patient case mix. In these, the size of the relation between volume and outcome (principally mortality) is reduced, or even disappears, compared with unadjusted data, although it is still considerable in several cases (table 1). 
Table 1 Summary of relation between volume and quality from best quality studies *

Procedure, service, or condition
Coronary artery bypass graft surgery
Paediatric heart surgery
Acute myocardial infarction
Percutaneous transluminal coronary angioplasty

Evidence

Slightly reduced risk of in hospital mortality in hospitals carrying out $>200$ procedures/year (OR $0.90,95 \%$ CI 0.82 to 0.98$)^{\prime \prime \prime 11 ~(s e e ~ f i g u r e) . ~}$

Reduced death rate in hospitals with $>300$ cases per year compared with hospitals with $<10$ cases and $<300$ cases. (OR $1 / 8$ and $1 / 3$ respectively)." No significant difference in in hospital but higher 6 months mortality and lower rate of reinfarction in hospitals with $<300$ beds (mortality $17 \%, \tau$ $12 \%)$. ${ }^{21}$ Significant negative relation between in hospital mortality and physician volume (coefficient $=-0.05$ ) but not hospital volume. ${ }^{21}$

No physician-volume relation found. Mortality declines by $0.1 \%$ for a 100 increase in annual number of hospital procedures (mean $\mathrm{n}$ of treatments $=$ 400). ${ }^{2 i}$

No significant association between physician volume and angiographic or clinical successes. ${ }^{1 *}$ Reduction in major complications when volume $>$ 400 year (OR 0.66). ${ }^{22}$ No physician-volume relation found for mortality, but more complications, emergency CABG, and longer duration of stay with physicians carrying out $<50$ procedures per year. ${ }^{23}$

Abdominal aortic aneurysm SMR $30 \%$ higher in hospitals with $<14$ patients/year, but no relation with surgeon found..$^{2+} 12 \%$ mortality for hospitals with $<6$ procedures compared with $5 \%$ in those $>38$ per year. Double the mortality in low volume surgeons $(<6)$ compared with high volume surgeons $(>26) .{ }^{25}$ Mortality declines by $1 \%$ for an increase of 4 operations / year / hospital (mean $n$ of treatments = 23 per year). No evidence of a surgeon volume effect. $2 \%$ Increased odds of dying if in hospital with $<21$ cases compared with $>21$. This risk difference greater for ruptured aneurysms. ${ }^{27}$

Amputation of lower limb (no trauma)

Gastric surgery

SMR $16 \%$ higher in hospitals with below average annual volume (mean $\mathrm{n}$ of treatments $=10.5) . .^{24}$

No significant difference between hospitals with below and above average annual volume (mean $\mathrm{n}$ of treatments $=24$ ).$^{24}$ Mortality declines by $1 \%$ for a 17 increase in the annual number of hospital operations (mean $n$ of treatments $=38) .{ }^{26}$ Surgeons carrying out $<1$ procedures annually associated with higher mortality than those doing $>1$. "No relation between physician volume and mortality (mean $\mathrm{n}$ of treatments $=8$ )..$^{26}$

Cholecystectomy

SMR $26 \%$ higher in hospitals with below average annual volume (mean $\mathrm{n}$ of treatments $=109) .{ }^{24}$ Hospitals performing $<168$ procedures a year had a mortality rate of $1.52 \%$ compared with $1.21 \%$ in those with higher volume. No further reduction in mortality found for next highest volume category.

No significant association with surgeon volume found. ${ }^{1 t}$

Intestinal operations (excluding cancer)

Hospital mortality higher $(8.3 \%)$ when $<40$ operations operations

performed a year than when $>40(5.9 \%)$. Surgeons with annual volume $>8$ also associated with lower mortality. ${ }^{1 .}$

SMR $14 \%$ lower in hospitals with below average annual volume (mean $\mathrm{n}$ of treatments $=73$..$^{24}$

Gall bladder diagnosis (Non-surgical)

Ulcer (non- surgical)

Knee replacement

Hip fracture

Neonatal care

Paediatric intensive care

Adult intensive care

Prostatectomy

Trauma care

No significant effect of volume.

Higher hospital volume associated with lower risk of complications (mean n of treatments $=3.5$ ).$^{2 m}$

No significant effect of hospital volume on mortality (mean $\mathrm{n}$ of treatments $=45)^{24}$

Infants $<28$ wks gestation had better survival in intensive care units $(>500$ days of ventilation/year) compared with special care units ( $<500$ days of ventilation/year). No difference for more mature infants. ${ }^{29}$

No significant association found between mortality and monthly volume. ${ }^{3+}$

No association between \% dying and monthly unit volume.

No significant differences found. ${ }^{31}$

No significant difference in mortality from major trauma and volume across accident and emergency departments with volumes ranging from $<10 / \mathrm{y}$ to $>90 / \mathrm{y}$ in 3 regions. (Further analysis of data from study by Nichol et al,

1995. $)^{32}$ No difference in mortality in a tertiary trauma unit for patients with mainly blunt injuries as it doubled in volume over a 4 year period. Surgeons carrying out $>200$ operations / year had greater rate of adverse events (especially posterior capsular opacification OR 2.5 )..$^{34}$

Risk of 30 day mortality was 2.5 times as high when treated in low experience hospitals ( $<43$ patients) than in a hospital having treated $>43$ patients (RR for 30 day mortality $=2.5)$. ${ }^{\text {i }}$

$15 \%$ reduction in mortality with surgeons treating $>29$ new cases year, bu no advantage of $>50$ compared with $>29$. "k

SMR $20 \%$ higher in hospitals with below average annual volume (mean $\mathrm{n}$ of treatments $=17) .{ }^{24}$ No significant association between volume and in hospital mortality (mean $\mathrm{n}$ of treatments $=50$ ) or surgeon volume (mean $\mathrm{n}$ of treatments $=8) .^{20}$

No significant differences in mortality or morbidity colorectal resection between surgeons with volumes ranging from 44 to 110 cases per year.

No significant association between mortality and either hospital or surgeon volume. ${ }^{26}$

5 Year mortality $60 \%$ lower in patients treated at a cancer unit which treated over $50 \%$ of patients with this cancer in the area."

$17 \%$ Lower rate of operative mortality in surgeons $>3$ operations $/$ year. $4 \%$ Reduction in 5 year mortality with surgeons treating $>6$ new cases per year. Most explained by reduced operative deaths. ${ }^{39}$

Patients treated by surgeons with highest volume ( 76 cases in 20 months) had lowest risk of complications (fistula) compared with lower volume surgeons in the same hosoital. ${ }^{\text {t0 }}$

Pancreatic cancer

^ All outcomes in this table are adjusted for case mix. Results of studies with less adequate adjustment for case mix (grade II and below) are not summarised here but are available in the full report. ${ }^{2}$ Mean volumes stated if reported in the paper. OR=odds ratio (the ratio of the odds of an adverse event occurring in a higher volume unit compared with a low volume unit; if the OR $<1$ then there is less risk of a poor outcome in the higher volume unit). 


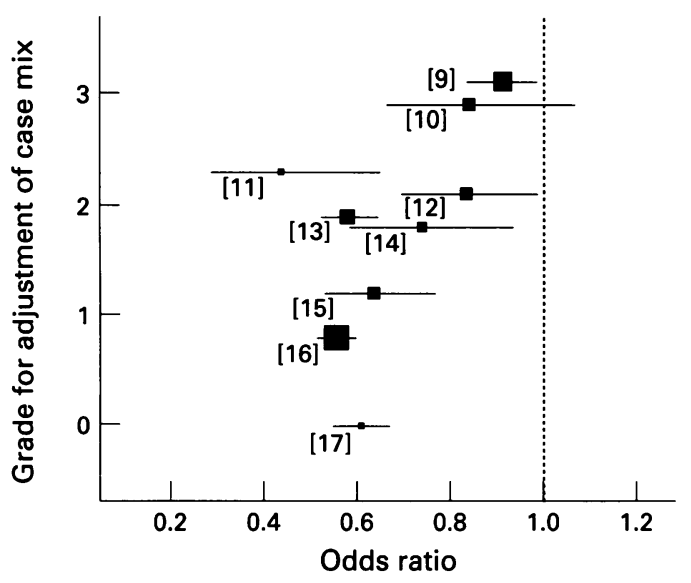

Benefit of higher annual volume of $C A B G$ surgery by adequacy of case mix adjustment. Source: updated analysis based on Sowden et al, 1995.' OR of 1 indicates no difference between $>200$ and $<200 . O R<1$ indicates reduced hospital mortality with values $>200$ a year. Numbers in [] are references.

The research is also limited by the narrow measures of outcome used, usually inpatient or 30 day mortality. Differences in mortalities found may also reflect other factors such as discharge policies rather than quality of care. The interpretation of these many publications is also complicated by the variable definitions of high and low volume both within and across procedures and the range of statistical techniques used to estimate any relation.

Research has mainly concentrated on the number of procedures carried out in a hospital rather than on the number performed by each clinician. Any true relation found between volume and outcome may be related to the volume or experience of the clinician carrying out the procedure, or alternatively it may be related to a whole host of variables such as operating room staff and surgical techniques used.

Finally, a positive relation between high volume and improved outcome can be interpreted in various ways. It might support the "practice makes perfect" hypothesis or a selective referral hypothesis, in which hospitals or doctors with good outcomes attract more patients. It may also be the case that higher volume hospitals attract better clinicians or support staff so producing a hospital level effect. Thus it is difficult with observational studies to uncover the relations between the many variables and the direction of any causality.

Two conclusions can be sustained from the existing publications on volume and outcome. Firstly, that the bulk of the research, because it does not sufficiently take into account case mix differences, probably overestimates the size of impact of volume on the quality of care. Secondly, because none of the research indicated that increasing the volume of activity over time resulted in changes in health outcomes, it is difficult to use findings of a positive relation between volume and outcome across hospitals or doctors to infer what would happen to healthcare outcomes if existing low volume units expanded.

This review did not explicitly consider the possible relation between the degree of specialisation of clinicians and quality of care or the related issue of multidisciplinary links. Where specialisation improves quality, then this will require care to be provided in a more coordinated way, and particularly for rarer conditions, sometimes in larger centres. The need may be met, however, in the more common conditions by a clearer division of labour within hospitals and links across hospitals rather than concentration of services in fewer hospitals. ${ }^{41}$

\section{Volume and costs}

It is often assumed that by concentrating hospital services into larger units, efficiency will be improved because of the operation of economies of scale. However, it is important to validate empirically the range of output over which average costs are expected to fall, and the scale at which costs may begin to rise.

Economies of scale refers to a situation in which long run average costs fall as the scale or volume of activity rises. Economies of scale are expected to be present where the fixed costs of providing a service are relatively high. For example, if a large investment in human and physical capital is required to produce any level of output, the cost of this investment is a fixed cost. As output increases, average costs will fall (over some range) as fixed costs are spread over larger volumes. However, increasing scale often brings additional sources of cost, and beyond some critical volume average costs are expected to begin to rise because of disproportionate economies of scale. ${ }^{42}$

Against this background, a systematic literature review ${ }^{3}$ was undertaken to critically appraise the evidence on economies of scale. Over 100 relevant studies were identified that used a range of statistical and other techniques of varying methodological quality. Study validity is also likely to be affected by problems of adjustment for case mix as comorbidities are important in determining patient costs. ${ }^{43}$

Overall, the results from the more reliable studies are largely consistent: if economies of scale are evident, they seem to be fully exploited in acute hospitals with 100-200 beds; hospitals with more than 300-600 beds show disproportionate economies of scale. In other words, hospitals below 100-200 beds may improve efficiency by increasing size, but expanding above this range will not necessarily reduce average costs, and if too large may increase average costs.

An issue of interest is whether increasing concentration by-for example, hospital mergers-can be expected to generate efficiency gains in the NHS through the exploitation of economies of scale. Publications which deal directly with gains from merger (mostly from the United States) have not generally shown dramatic improvements in operating practices ${ }^{44}$ or expected savings. ${ }^{45-49}$ If, as the research evidence suggests, economies of scale are exhausted at relatively low levels, mergers cannot be expected to offer opportunities for improvements in efficiency when the constituent hospitals are already above the threshold level. 
This result may seem counterintuitive: it is often assumed that one hospital must be more efficient than two smaller ones as duplication of management at the very least, may be eliminated. However, this may not be the case; it is possible that more management is required to run a large organisation than two small ones. More fundamentally, it is the total cost per episode and not just the management cost that is important, and that has been studied. Even when larger hospitals have fewer managers, they may not gain in efficiency. This may be due to a decline in standards of management leading to reduced efficiency, or to a redistribution of management tasks to non-traditional managers, so reducing output. To examine this question properly would require studies which considered simultaneously both the cost and outcomes data.

Table 2 puts these results in an English context. However, several caveats must be emphasised in applying these results. Firstly, the review has evaluated cost economies in the production of acute services and not examined the optimal scale for subacute services-for example, in cottage hospitals. No relevant publication was identified that examined economies in training. Secondly, publications on economies of scale are directly relevant only to those hospitals which are technically efficient. Where hospitals are characterised by excess capacity and unused facilities, concentration may (but need not) ${ }^{49}$ be an efficient means of lowering overall unit costs by reducing surplus capacity or an expeditious way locally to restructure health services.

The evidence from the review of links between volume and quality already discussed shows that for some specialties there may be quality gains from increased volume. There might also be links between specialties that improve quality (research evidence in this area is scant). Together these may imply quality gains from hospital scale that compensate for reduced efficiency.

In the light of these caveats, the principle tentative conclusions from the literature review are that there is no evidence that cost savings can be secured merely by increasing scale beyond 200 beds and that it is likely that large hospitals (above 600 beds) have inefficiencies, although these may be offset in other ways.

\section{Patient access}

Consideration of the potential effects of concentration of hospital services on patient

Table 2 Distribution of English acute hospitals by size (including acute sites in combined Trusts)

\begin{tabular}{lllcc}
\hline $\begin{array}{l}\text { Beds } \\
(n)\end{array}$ & $\begin{array}{l}\text { Acute hospitals } \\
(n)\end{array}$ & $\begin{array}{l}\text { \% Total acute } \\
\text { hospitals }(n)\end{array}$ & $\begin{array}{l}\text { Acute beds } \\
(n)\end{array}$ & $\begin{array}{l}\text { \% Total acute } \\
\text { beds }(n)\end{array}$ \\
\hline$<100$ & 90 & 22.0 & 5002 & 3.05 \\
$100-200$ & 59 & 14.1 & 8491 & 6.0 \\
$200-300$ & 51 & 12.5 & 12513 & 8.9 \\
$300-400$ & 55 & 13.4 & 19260 & 13.7 \\
$400-500$ & 48 & 11.7 & 21147 & 15.0 \\
$500-600$ & 39 & 9.5 & 21224 & 15.1 \\
$>600$ & 67 & 16.4 & 53320 & 37.8 \\
\hline
\end{tabular}

Source=IHSM Health and Social Services Yearbook 1996/7.

International research suggests that cost per case is minimised in hospitals with $<300-600$ beds and $>100-200$ beds, assuming such hospitals are operating efficiently. access is also important. The systematic review ${ }^{4}$ identified nearly 50 studies of patient access which in general provide poor quality evidence. The research in this area focuses almost exclusively on the relation between observed rates of use and distance (or travel time) as a proxy for access. This is, at best, a partial approach because distance is only one of several likely factors-for example, opening hours, personal mobility, sex, language, or socioeconomic group-affecting access. Also, most of the studies identified were cross sectional and were poorly controlled for the effects of confounding variables.

Bearing in mind the important qualification on the quality of many of the studies, the review suggests that: there is evidence of a reduction in access with distance (distance decay) particularly in areas where perceptions of need and importance may be $l o w^{50}$-for example, mammography, ${ }^{51}$ cervical cytology, ${ }^{52}$ and aftercare for alcoholism ${ }^{53}$-but also self referral to accident and emergency departments. ${ }^{54-56}$ One study showed that positive systematic action such as a call and recall system improved the use of a centralised screening programme in the United Kingdom. ${ }^{54}$ Distance may not affect attendance when the clinic is related to cancer. ${ }^{57}$

There is conflicting evidence for inpatient services present in research from North America, ${ }^{168-62}$ whereas that from the United Kingdom finds evidence of distance decay in each case. ${ }^{5363-67}$ Although not conclusive, the evidence is consistent with the view that accessibility is likely to be adversely affected by the distance from the hospital. However, these studies often poorly adjust for factors such as severity and need. A few studies have reported reductions in the frequency of patients visiting the hospital as distance increases. ${ }^{68-70}$

There is mixed evidence about the impact of distance on health outcome. Mortality from asthma, ${ }^{71}{ }^{72}$ diabetes, and perinatal mortality is increased with distance, ${ }^{72}$ but not for a range of other diseases such as breast and cervical cancer (United Kingdom study) ${ }^{72}$ or serious road traffic accidents (Norfolk study).$^{73}$ In Finland, a study showed that concentration of a radiotherapy facility did not adversely affect survival rates from breast or prostatic cancer. ${ }^{74}$ However, a French study reported that people in more isolated rural areas had a more advanced stage of colorectal cancer when diagnosed. ${ }^{75}$

When services are concentrated, the effect can be to shift some of the costs of health care from the NHS to patients and their carers. ${ }^{7677}$ For example, people needing radiotherapy for cancer and who have no independent cheap transport may spend all day getting to and from a cancer centre. ${ }^{57}$ In assessing the effects of increased concentration on access and use, the implications of cost shifting, particularly on disadvantaged groups, should not be overlooked.

\section{Conclusions}

The literature on links between volume of activity and clinical outcomes suggests that for 
some procedures or specialties there may be some quality gains as hospital or clinician volume increases. In other areas the research suggests an absence of significant volume gains. Generalisation is clearly not possible on the basis of these results. Hence, it would not be warranted to extrapolate the findings, whether positive or negative, outside the sample ranges, or for the many procedures for which the research evidence is too poor to suggest any conclusion.

When volume is associated with quality, the direction of causation is not established and there is no good evidence to indicate that increasing volume will actually result in an improvement in healthcare outcomes. Nevertheless, in the few cases in which links between volume and quality have been suggested by more reliable studies, these might well act as prompts for investigation by purchasers or clinicians. In some cases, the indicated thresholds are relatively low, and could be reached through specialisation of tasks within a hospital rather than an increase in the size of the provider.

Optimal configuration of services will depend on the links between volume and quality suggested for the relevant specialties, together with links between specialties and the impact that scale may have on costs (as both scale and market dominance may breed inefficiency), on access, on equity, and on responsiveness (which may depend on choice). The results summarised in this paper may be helpful in balancing these considerations.

We acknowledge the support of members of the NHS Centre for Reviews and Dissemination Information Service in helping to develop the search strategy and in the identification of relevant publications.

1 NHS Centre for Reviews and Dissemination. Concentration and choice in the provision of hospital services. Summary report. York: University of York, 1996. (CRD Report 8.)

2 NHS Centre for Reviews and Dissemination. Concentration and choice in the provision of hospital services. The relationship between hospital volume and quality of health outcomes. York: between hospital volume and quality of health outcomes.

3 NHS Centre for Reviews and Dissemination. Concentration and choice in the provision of hospital services. The relationship between volume and the scope of activity and hospital costs. York: University of York, 1996. (CRD Report 8 (part II).

4 NHS Centre for Reviews and Dissemination. Concentratio and choice in the provision of hospital services. The relationship between concentration, patient accessibility and utilisation of services. York: University of York, 1996. (CRD Report 8 (part III).)

5 Hofer TP, Hayward RA. Identifying poor-quality hospitals. Med Care 1996;34:737-53.

6 Davenport RJ, Dennis MS, Warlow CP. Effect of correcting outcome data for case-mix: an example from stroke medicine. BMF 1996;312:1503-5.

7 Sowden AJ, Deeks JJ, Sheldon TA. Volume and outcome in coronary artery bypass graft surgery: true association or artefact? $B M F$ 1995;311:151-5.

8 Jones J, Rowan K. Is there a relationship between the volume of work carried out in intensive care and its outcome? Int $\mathcal{F}$ Technol Assess Health Care 1995;11:762-9.

9 Clarke RE. Outcome as a function of annual coronary artery bypass graft volume. Ann Thorac Surg 1996;61:17-20.

10 Hannan EL, Kilburn H, Racz M, Shields E, Chassin MR. Improving the outcomes of coronary artery bypass surgery in New York State. $\Im A M A$ 1994;271:761-6.

11 Maerki SC, Luft HS, Hunt SS Selecting categories of patients for regionalisation. Med Care 1986;24:148-58.

12 Showstack JA, Rosenfeld KE, Garnick DW, Luft HS, Schaffazrick RW, Fowles J. Association of volume with outcome of coronary artery bypass graft surgery, scheduled $v$ non-scheduled operations. $¥ A M A$ 1987;257:785-9.

13 Luft HS, Bunker JP, Enthoven AC. Should operations be regionalised? The empirical relationship between surgical volume and mortality. $N$ Engl f Med 1979;301:1364-9.

14 Hanne and mortality. N Engl f Med 1979;301:1364-9. A. Investigation of the relationship between volume and mortality for surgical procedures performed in New York state hospitals. $\mathscr{F} A M A$ 1989;262:503-10.
15 Rosenfeld K, Luft HS, Garnick DW, McPhee SJ. Changes in patient characteristics and surgical outcomes for coronary artery bypass surgery 1972-82. Am f Public Health 1987;77:498-500

16 Grumbach K, Anderson GM, Luft HS, Roos LL, Brook R Regionalization of cardiac surgery in the United States and Canada: geographic access, choice, and outcomes. $\mathfrak{F} A M A$ 1995;274:1282-9.

17 Johnson AN. The relationship between volume, quality and outcome in hospital care delivery [PhD thesis]. Minnesota: University of Minnesota, 1988:159.

18 Talley JD, Mauldin PD, Leesar MA, Becker ER. A prospective randomised trial of 0.010 versus 0.014 balloon PTCA systems and interventional fellow versus attending physician as primary operator in elective PTCA: economic, technical and clinical end points. Fournal of Intervention Cardiology 1995;8:623-32.

19 Jenkins KJ, Newburger JW, Lock JE, Davis RB, Coffman GA, Iezzoni LI. In-hospital mortality for surgical repair of congenital defects: preliminary observations of variation by hospital caseload. Pediatrics 1995;95:323-30.

20 Barbash GI, White HD, Modan M, Diaz R, Hampton JR, Heikkila J. Outcome of thrombolytic therapy in relation to hospital size and invasive cardiac services. Arch Intern Med 1994;154:2237-42.

21 Kelly JV, Hellinger FJ. Heart disease and hospital deaths: an empirical study. Health Serv Res 1987;22:369-95.

22 Kimmel SE, Berlin JA, Laskey WK. The relationship between coronary angioplasty procedure volume and major complications. $\mathscr{F} A M A$ 1995;274:1137-42.

23 Shook TL, Sun GW, Burnstein S, Eisenhauer AC Matthews RV. Comparison of percutaneous translumina angioplasty outcome and hospital costs for low volume and high volume operators. Am f Cardiol 1996;77:331-6

24 Flood AB, Scott WR, Ewy W. Does practice make perfect? Part 1: the relation between hospital volume and outcomes for selected diagnostic categories. Med Care 1984;22:98114 .

25 Veith FJ, Goldsmith J, Leather RP, Hannan EL. The need for quality assurance in vascular surgery. $\mathcal{F}$ Vasc Surg 1991; 13:523-6.

26 Kelly JV, Hellinger FJ. Physician and hospital factors associated with mortality of surgical patients. Med Care 1986;24:785-800.

27 Katz DJ, Stanley JC, Zelenock GB. Operative mortality rates for intact and ruptured abdominal aortic aneurysms in Michigan: an eleven year statewide experience. $\mathcal{F}$ Vasc Surg 1994;19:804-17.

28 Benjamin G. Three essays on volume, complications and hospital resource use: the case of knee replacement surgery [PhD thesis]. Indiana University, 1995:114.

29 Field D, Hodges S, Mason E, Burton P. Survival and place of treatment after premature delivery. Arch Dis Child 1990; 66:408-11.

30 Pollack MM, Cuerdon TT, Patel KM, Ruttimann UE, Getson PR, Levetown $M$. Impact of quality of care factors on pediatric intensive care unit mortality. $\mathscr{A} A M A 1994$ pediatric inte

31 Wennberg JE, Roos N SL, Schori A, Jaffe R. Use of claims data systems to evaluate health care outcomes.Mortality and reoperation following prostatectomy. $\mathscr{f} A M A 1987$ 257:933-6.

32 Nichol J, Turner J, Dixon S. The cost-effectiveness of the regional trauma system in the north west Midlands. Sheffield: University of Sheffield, 1995

33 Waddell TK, Kalman PG, Goodman SJL, Girotti MJ. Is outcome worse in a small volume Canadian trauma cutcome worse in a small volum

34 Schein OD, Steinberg EP, Javitt JC, et al. Variation in cataract surgery practice and clinical outcomes. Ophthamology 1994;101:1142-52.

35 Stone VE, Seage GR, Hertz T, Epstein AM. The relation between hospital experience and mortality for patients with AIDS. fAMA 1992;268:2655-61.

36 Sainsbury R, Haward B, Rider L, Johnston C, Round C. Influence of clinician workload and patterns of treatmen Infuence of clinician workead and pat 1995;345:1265-70.

37 Sagar PM, Hartley MN, MacFie J, Taylor BA, Copeland GP. Comparison of individual surgeon's performance. Dis Colon Rectum 1996;39:654-8.

38 Harding MJ, Paul J, Kaye SB. Management of malignant teratoma: does referral to a specialist unit matter? Lance 1993;341:999-1002.

39 Matthews HR, Powell DJ, McConkey CC. Effect of surgica experience on the results of resection for oesophageal carcinoma. Br 7 Surg 1986;73:621-3.

40 Yeo CJ, Cameron JL, Maher MM, et al. A prospective randomized trial of pancreaticogastrostomy versus pancreaticojejunostomy after pancreaticoduodenectomy. Ann Surg 1995;222:580-92.

41 Clinical Outcomes Group. Improving outcomes in breast cancer: the manual. London: NHS Executive, 1996:34-5.

42 Feldstein PJ. Health care economics. New York: Delmar, 1993:222-30

43 Shwartz M, Iezzoni LI, Moskowitz MA, Ash AS, Sawitz E. The importance of comorbidities in explaining differences in patient costs. Med Care 1996;34:767-82.

44 Alexander JA, Halpern MT, Lee SD. The short-term effects of merger on hospital operations. Health Serv Res 1996;30:827-47.

45 Treat TF. The performance of merging hospitals. Med Care 1976;14:199-209. 
46 Whittaker GF. The evaluation of a merged hospital system. Application of the interrupted time series desion. Evaluation Review 1981;5:68-89.

47 Mullner RM, Anderson RM. A descriptive and financia ratio analysis of merged and consolidated hospitals: US 1980-5. Advances in Health Economics and Health Service 1980-5. Advances in Heat
Research 1987;7:41-58

48 Bogue RJ, Shortell SM, Sohn MW, Manheim LM, Bazzoli $\mathrm{G}$, Chan C. Hospital reorganisation after merger. Med Care 1995;33:676-86.

49 Schwartz WB, Joskow PL. Duplicated hospital facilities How much can we save by consolidating them? $N$ Engl $f$ Med 1980;303:1449-57.

50 Simon JL, Barton Smith D. Change in location of a studen health service: a quasi-experimental evaluation of the effects of distance on utilization. Med Care 1973;11:59-67.

51 Haiart DC McKenzie I Henderson J Pollock W, McQueen DDV, Roberts MM, Forrest AP. Mobile breast McQueen DDV, Roberts MM, Forrest AP. Mobile breast screening: factors affecting uptake, efforts to increase
response and accessability. Public Health. 1990;104:239respo

52 Bentham G, Hinton J, Haynes R, Lovett A, Bestwick C. Factors affecting non-response to cervical cytology screening in Norfolk, England. Soc Sci Med 1995;40:131-5.

53 Fortney JC, Booth BM, Blow FC, Bunn JY. The effects of travel barriers and age on the utilization of alcoholism treatment aftercare. Am $\mathcal{f}$ Drug Alcohol Abuse 1995; 21:391-406.

54 McKee CM, Gleadhill DN, Watson JD. Accident and emergency attendance rates: variation among patients from different general practices. Br $\mathcal{F}$ Gen Pract 1990;40:150-3.

55 Walsh $M$. Geographical factors and $A$ and $E$ attendance. Nursing Standard 1990;5:28-31.

56 Bentham G, Haynes R. Health, personal mobility and the use of health services in rural Norfolk. Fournal of Rural use of health services
Studies $1985 ; 1: 231-9$.

57 Greenberg ER, Dain B, Freeman D, Yates J, Korson R Referral of lung cancer patients to university hospital cancer centers. A population-based study in two rural states. Cancer 1988;62:1647-52.

58 Anderson GM, Lomas J. Regionalization of coronary artery bypass surgery. Effects on access. Med Care 1989;27:288 96.

59 Roos NP, Lyttle D. The centralization of operations and access to treatment: total hip replacement in Manitoba. Access to treatment: total hip repla

60 Roos LL, Sharp SM. Innovation, centralization, and growth. Coronary artery bypass graft surgery in Manitoba. Med Care 1989;27:441-52.
61 Gittelsohn A, Powe NR. Small area variations in health care delivery in Maryland. Health Serv Res 1995;30:295-317.

62 Strong NP, Wigmore W, Smithson S, Rhodes S, Woodruf G, Rosenthal AR. Daycase cataract surgery. Br f Ophthalmol 1991;75:731-3.

63 Black N, Langham S, Petticrew M. Coronary revascularisation: why do rates vary geographically in the UK? $\mathcal{F}$ Epidemiol Community Health 1995;49:408-12.

64 Wood PW. Geographical equity and inpatient hospital care: an empirical analysis. Departments of community medicine and political economy. Aberdeen: Health Economics Research Unit, University of Aberdeen, 1985.

65 Packer C. Emergency admissions to the Alexandra Hospital, Redditch. Worcester: North Worcestershire Health $\mathrm{Au}-$ thority, 1995.

66 Slack R, Ferguson B, Ryder S. Analysis of hospitalisation rates by electoral ward: relationship to accessibility and deprivation data. York: York Health Economics Consortium, 1994.

67 Dalziel M, Garrett C. Intraregional variation in treatment of end stage renal failure. $B M \mathscr{Y} 1987 ; 294: 1382-3$.

68 Cross KW, Turner RD. Patient visiting and the siting of hospitals in rural areas. Br f Prev Soc Med 1974;28:276-80.

69 Giacoia GP, Rutledge D, West K. Factors affecting visitation of sick newborns. Clin Pediatr 1985;24:259-62.

70 Haynes RM, Bentham CG. Community hospitals and rural accessibility. Farnborough: Teakfield, 1979.

71 Wilson JMG. Asthma deaths in Scotland 1965-80. Scot Med f 1984;29:84-9.

72 Jones AP. Health service accessibility and health outcomes. Norwich: University of East Anglia, 1996.

73 Jones AP, Bentham G. Emergency medical service accessibility and outcome from road traffic accidents. Public Health 1995;109:169-77.

74 Karjalainen S. Geographical variation in cancer patient survival in Finland: chance, confounding, or effect of vival in Finland: chance, confounding, or effect of

75 Launoy G, Le Coutour X, Gignoux, Pottier D, Dugleux G. Influence of rural environment on diagnosis, treatment, and prognosis of colorectal cancer. $f$ Epidimiol Community Health 1992;46:365-7.

76 Kohli HS, Teo PYK, Howie FMC, Dobson HM. How accessible is the breast screening assessment centre for Lanarkshire women? Health Bull 1995;53:153-8.

77 Torgerson DJ, Donaldson C, Reid DM. Private versus social opportunity cost of time: valuing time in the demand for health care. Health Econ 1994;3:149-55. 